\title{
Enshi sulfur dioxide residues in food risk assessment
}

\author{
Xiaohong $\mathrm{He}^{1 *}$, Rangpeng $\mathrm{Wu}^{1}$, Meiqiong $\operatorname{Tan}^{1}$, Zhihao $\mathrm{Mu}^{1}$, Jihua $\mathrm{Liu}^{1}$ \\ ${ }^{1}$ Enshi Center for Disease Control and Prevention, Enshi, Hubei, China
}

\begin{abstract}
From 2012 to 2019, the risk monitoring of food chemical contaminants and harmful factors in Enshi Prefecture found that the sulfur dioxide residues in food exceeded the standard seriously, and the sample exceeded the standard rate of $8.16 \%-17.7 \%$, including pickled vegetables, edible starch, and dried vegetables. Among them, the sulfur dioxide content exceeded the standard rate of $63.64 \%, 48.00 \%, 30.09 \%$, and the risk quotient (HQ) was $0.464,0.075$, and 0.527 , respectively. Due to the low consumption of dried vegetables, pickled vegetables, edible starch and edible fungus products, they are still at a safe level, but the cumulative effect of sulfur dioxide residues in the diet may pose health risks to consumers.
\end{abstract}

\section{Introduction}

Food safety is a major livelihood issue related to the health and life safety of the people. In the "GB 2760-2014 National Food Safety Standard Food Additives Use Standard" ${ }^{11]}$, sulfur dioxide is widely used as a food additive in food. At the same time, China has strict regulations and management on the use of sulfur dioxide. Enshi CDC food safety risks of long-term monitoring, we found 2012--2019 Residues in the amount of sulfur dioxide in foods Enshi the standard. Active sulfur dioxide in food research and health risk assessment, providing technical support and scientific basis for long-term monitoring of food additives in Enshi.

\section{Materials and Methods}

\subsection{Sample collection}

A total of 714 samples were randomly collected in small restaurants, markets and stores in Enshi Prefecture, Hubei Province, China. during 2012 to 2019 . The sample types included pickled vegetables, food starch, soy products, edible mushrooms, dried vegetables, nuts and seeds cereal products, etc.

According to the food safety risk monitoring manual, the sample size of each product is at least $1.0 \mathrm{~kg}$. After purchase, the samples were immediately sent to a laboratory for testing after crushing ${ }^{[2-3]}$.

\subsection{Analysis procedure}

The sample was pulverized, mixed, uniformly $5 \mathrm{~g}$ weighed sample into the distillation flask. Add $250 \mathrm{~mL}$ of distilled water, install the condensing device, insert the lower end of the condensing tube into the liquid level of the iodine flask pre-prepared with $25 \mathrm{~mL}$ of lead acetate absorption solution, then add $10 \mathrm{~mL}$ of hydrochloric acid solution to the distillation flask, stop it immediately, heat it for distillation, about $200 \mathrm{~mL}$, away from the liquid surface so that the lower end of the condensing duct, redistillation $1 \mathrm{~min}$, while the blank test.

To remove iodine flask were added $10 \mathrm{~mL}$ of hydrochloric acid, $1 \mathrm{~mL}$ of starch indicator solution, then shake with iodine standard solution was titrated to the color of the solution turns blue and 30s do not fade, the record Iodine Titration volume of solution consumed. The standard solution of iodine titration volume, calculated content of sulfur dioxide in food analysis.

\subsection{Risk assessment}

\subsubsection{Dietary exposure assessment}

Dietary exposure assessment model is mainly based on the Environmental Protection Agency released. According to the monitored sulfur dioxide residue and food consumption data, calculate the estimated daily intake of sulfur dioxide in food according to formula (1) ${ }^{[4-5]}$.

$$
E E D=\frac{\sum_{i=1}^{n}\left(C_{i} \times F_{i} \times P_{i} \times E_{i}\right) \times \mathrm{ABS} \times \mathrm{EF} \times \mathrm{ED}}{\mathrm{BW} \times \mathrm{AT}}
$$

Where: EED: daily exposure of sulfur dioxide $[\mathrm{mg} /(\mathrm{kg} \cdot \mathrm{d})]$; Ci: exposure concentration of sulfur dioxide $(\mathrm{mg} / \mathrm{kg})$; Fi: daily intake (kg/d); Pi: processing Factor; Ei: edible factor; ABS: gastrointestinal absorption coefficient of sulfur dioxide; EF: exposure frequency; ED, exposure duration; BW: human body weight $(\mathrm{kg})$; AT: flattening time $365 \times$ ED. Assuming that the average age of people for 70 years, adult body weight of $60 \mathrm{~kg}, \mathrm{Pi}, \mathrm{Ei}, \mathrm{ABS}$ values are 1, EF 365 days.

\subsubsection{Risk quotient}

\footnotetext{
*Corresponding author: t0321121@163.com
} 
The risk description of chemical hazards with thresholds is generally carried out using the risk quotient method HQ. The risk quotient (HQ) is calculated by EED and ADI according to the following formula (2).

$H Q=\frac{E E D}{A D I}$

Where, HQ risk quotient value of all people, and ADI acceptable daily intake of sulfur dioxide. In this study, the ADI for sulfur dioxide was $0.7 \mathrm{mg} /(\mathrm{kg} \cdot \mathrm{bw} \cdot \mathrm{d})$ set by JECFA ${ }^{[6]}$.

Its meaning is: when $\mathrm{HQ}>1$, it means there is a risk, the greater the value, the greater the risk.

\subsubsection{Maximum safe consumption}

The maximum safe daily consumption (Fimax) of sulfur dioxide residue food is calculated according to the following formula (3).

$F i_{\text {max }}=\frac{B W \times A D I}{C_{i}}$

Where: Fimax: indicates the maximum safe daily consumption $(\mathrm{kg} / \mathrm{d})$; BW: body weight represents the crowd $(\mathrm{kg})$; $\mathrm{Ci}$ : represents food in sulfur dioxide content $(\mathrm{mg} / \mathrm{kg})$.

\section{Results and discussion}

Similar studies on sulfur dioxide residues in fresh vegetables, edible fungi and dried fruits have been reported ${ }^{[7-8]}$. Table 1 lists the residual concentration and risk quotient of sulfur dioxide in 714 samples. In general, the average concentration of sulfur dioxide in dried vegetables, pickled vegetables, edible starch and edible fungus products are higher than the MRLs(Dried vegetables, pickled vegetables, food starch and edible fungi articles sulfur dioxide limits were 200, 100, 30 and $50 \mathrm{mg} / \mathrm{kg}$ ), and the risk quotient (HQ) is $0.527,0.464$, 0.075 , and 0.025 , respectively. Due to the low consumption of dried vegetables, pickled vegetables, edible starch and edible fungus products, they are still at a safe level, but the cumulative effect of sulfur dioxide residues in the diet may pose health risks to consumers. These results are consistent with previous research results.

Table 1 different food categories sulfur dioxide and residual concentration risk quotient

\begin{tabular}{|c|c|c|c|c|c|c|c|}
\hline Category & $\begin{array}{c}\text { Number of } \\
\text { samples }\end{array}$ & $\mathrm{Ci}(\mathrm{mg} / \mathrm{kg})$ & $\begin{array}{c}\mathrm{Max} \\
(\mathrm{mg} / \mathrm{kg})\end{array}$ & Excessive rate(\%) & $\begin{array}{c}\mathrm{Fi} \\
(\mathrm{kg} / \mathrm{d})\end{array}$ & $\begin{array}{c}\text { EED } \\
\mathrm{mg} /(\mathrm{kg} \cdot \mathrm{d})\end{array}$ & HQ \\
\hline Dried vegetables & 216 & 2170 & 6654 & 30.09 & 0.0102 & 0.369 & 0.53 \\
\hline Pickled vegetables & 11 & 1910 & 7362 & 63.64 & 0.0102 & 0.325 & 0.46 \\
\hline Edible starch & 25 & 717 & 5853 & 48.00 & 0.0044 & 0.053 & 0.075 \\
\hline Edible fungus products & 117 & 303 & 5712 & 7.69 & 0.0034 & 0.017 & 0.025 \\
\hline Bean products & 92 & 171 & 6294 & 5.43 & 0.0118 & 0.034 & 0.048 \\
\hline Nuts and seed products & 85 & 55.8 & 2055 & 0 & 0.0038 & 0.004 & 0.005 \\
\hline Grain milled products & 6 & 30.5 & 38.9 & 0 & 0.0135 & 0.007 & 0.010 \\
\hline Fresh edible fungus & 101 & 19.2 & 49.2 & 0 & 0.0034 & 0.001 & 0.002 \\
\hline Starch products & 56 & 12.6 & 15.4 & 1.79 & 0.0044 & 0.001 & 0.001 \\
\hline Cereal products & 5 & 11.8 & 14.0 & 0 & 0.28 & 0.055 & 0.079 \\
\hline
\end{tabular}

In terms of sample sampling, Table 2 shows that samples with excess sulfur dioxide are mainly from small restaurants, farmer's markets and shops, and their excess rates are $16.86 \%, 11.11 \%$, and $6.45 \%$, respectively. These places are where local people mainly buy food.

Table 2 Different types of sampling sites exceeded the rate of sulfur dioxide

\begin{tabular}{ccccc}
\hline $\begin{array}{c}\text { Sampling } \\
\text { session }\end{array}$ & $\begin{array}{c}\text { Number } \\
\text { of } \\
\text { samples }\end{array}$ & $\mathrm{Ci}(\mathrm{mg} / \mathrm{kg})$ & $\operatorname{Max}(\mathrm{mg} / \mathrm{kg})$ & $\begin{array}{c}\text { Excessive } \\
\text { rate(\%) }\end{array}$ \\
\hline $\begin{array}{c}\text { Farmers } \\
\text { market }\end{array}$ & 421 & 1240 & 6654 & 16.86 \\
$\begin{array}{c}\text { store } \\
\text { Roadside } \\
\text { stalls }\end{array}$ & 279 & 216 & 1428 & 6.45 \\
$\begin{array}{c}\text { Small } \\
\text { restaurants } \\
\text { Total }\end{array}$ & 9 & 34.9 & 69.5 & 0 \\
\hline
\end{tabular}

For sulfur dioxide residues in food, we calculated according to the formula (3), adult day dried vegetables, pickled vegetables and other foods, the maximum safe intake does not exceed $0.21 \mathrm{~kg}, 0.42 \mathrm{~kg}, 0.84 \mathrm{~kg}$. However, when the residual sulfur dioxide in dried vegetables is $2170 \mathrm{mg} / \mathrm{kg}$, the safe daily intake is only $0.019 \mathrm{~kg}$.

Sulfur dioxide as a food additive, because of having a bleaching action, antioxidant and preservation, food preservation which is widely used in the food production process. Because the children in the formative years, a variety of food demand, sulfur dioxide dietary exposure risk is greater. Therefore, sulfite overuse and misuse may have potential adverse effects on human health.

In this exposure assessment process, we assume that processed foods factors, edible part of the factor, gastrointestinal absorption coefficient are less 1 part of the sample number, representativeness is not strong, which give exposure assessment of sulfur dioxide added to the uncertainty.

\section{Conclusions}

This study provides Enshi sulfur dioxide residues in food risk assessment to the general population. According to the "GB 2760-2014 Food Safety National Standards for the Use of Food Additives", the excess rate of sulfur dioxide samples in different food categories varies greatly. Among them, pickled vegetables, edible starch, and dried vegetables have the highest sulfur dioxide content, which is $63.64 \%$, respectively. The risk quotient (HQ) of $48.00 \%$ and $30.09 \%$ were $0.464,0.075$ and 0.527 respectively. Due to the low consumption of pickled vegetables, edible starch and dried vegetables, they are still at a safe level, but the cumulative effect of sulfur dioxide residues in the diet may pose health risks to consumers. 
In order to prevent people, especially children in the diet overexposure sulfur dioxide, it is still necessary to reduce and limit the use of sulphites and sulfur dioxide by law enforcement activities, and called for tighter regulation of public education and implementation of integrated management additive method, Ensure food safety.

\section{References}

1. HFPC. Food Additives using standards. GB 27602014. Beijing (China): Health and Family Planning Commission of China. (2014).

2. Fang, Yanyan, et al. "Human health risk assessment of pesticide residues in market-sold vegetables and fish in a northern metropolis of China." Environ, Pollut Res Int 22.8(2015).

3. Vlachou, Christina, et al. "Risk assessment of nitrites for the Austrian adult population with probabilistic modelling of the dietary exposure." Food and Chemical Toxicology:111480(2020).

4. Zuo, Tian Tian, et al. "Innovative health risk assessment of heavy metals in Chinese herbal medicines based on extensive data." Pharmacological Research:104987(2020).

5. Rome, Joint Fao/Who Food Standards Programme, et al. "General standard for food additives, 2011." (2011).

6. Organization, Geneva World Health . "Evaluation of certain food additives and contaminants: forty-first report of the Joint FAO/WHO Expert Committee on Food Additives [meeting held in Geneva from 9 to 18 February 1993]." Geneva World Health Organization (1993).

7. Lou, Tiantian, et al. "Monitoring, exposure and risk assessment of sulfur dioxide residues in fresh or dried fruits and vegetables in China." Food Additives \& Contaminants Part A 34.6(2017).

8. Vandevijvere, S., et al. "Estimate of intake of sulfites in the Belgian adult population." Food Additives \& Contaminants Part A 27.8:1072-1083 (2010). 